\title{
CONTRIBUIÇÕES DE NIETZSCHE PARA A DISCUSSÃO DE CASOS DE INTERNAÇÕES MANICOMIAIS DE MULHERES
}

\section{Nietzsche's contributions for the Discussion of Cases of Woman mental internments}

Luciene Marques de Lima ${ }^{1}$

Resumo: Este artigo busca compreender como o conjunto de normas e regras sociais - a moralque define "o que é uma mulher" desencadeou reações sociais coercitivas e reguladoras que resultaram em violentas internações compulsórias em manicômios brasileiros no século XIX e meados do século XX. A autoria das internações foi de um homem da família: pai, irmão, marido, como uma espécie de castigo ou punição por atitudes consideradas por eles inadequadas para uma mulher. Este detalhe permitiu uma aproximação com a filosofia nietzschiana e uma discussão sobre a moralidade dos costumes referentes à mulher. Ainda em diálogo com a filosofia de Nietzsche, este estudo aborda uma possibilidade para a elaboração de outros costumes.

Palavras-chave: Moralidade dos costumes. Violência. Mulheres.

\begin{abstract}
This article seeks to understand how the set of social norms and rules - the moral- that defines "what is a woman" triggered coercive and regulatory social reactions that resulted in violent compulsory hospitalizations in Brazilian insane asylums in the nineteenth and mid-twentieth centuries. The authorship of hospitalizations was of a family man: father, brother, husband, as a kind of punishment or punishment for attitudes considered by them inappropriate for a woman. This detail allowed an approximation with Nietzschean philosophy and a discussion about the morality of the customs concerning women. Still in dialogue with Nietzsche's philosophy, this study addresses a possibility for the elaboration of other customs.
\end{abstract}

Keywords: Morality of customs. Violence. Women.

\footnotetext{
${ }^{1}$ Mestre em Psicologia pela Universidade Federal de Goiás. Graduada em Fisioterapia pela Universidade Estadual de Goiás. Este estudo é resultante do trabalho de conclusão da disciplina intitulada "Leituras do problema de gênero a partir de Nietzsche e Butler" ministrada pela Prof ${ }^{\mathrm{a}} \mathrm{Dr}^{\mathrm{a}}$ Adriana Delbó Lopes, no primeiro semestre do ano de 2019, no Programa de Pós-Graduação em Filosofia da Faculdade de Filosofia da Universidade Federal de Goiás-doutorado.
} 


\section{INTRODUÇÃO.}

Tomando a filosofia de Nietzsche como uma crítica genealógica à modernidade, este artigo adota trechos de sua obra e fragmentos de seus pensamentos como aporte orientador para uma reflexão acerca do papel social atribuído à mulher na sociedade Ocidental. Muito foi e permanece sendo dito e escrito sobre o pensamento nietzschiano acerca das mulheres. De machista e ressentido com as mulheres a um profundo conhecedor da realidade e dos poderes que atravessam o cotidiano feminino, e um crítico contumaz do papel que a sociedade moderna delegou às mesmas, muitas qualificações têm sido atribuídas a Nietzsche em reação aos seus escritos sobre as mulheres.

Maresca (2001) ao discutir a emancipação da mulher através dos parágrafos 231 a 239 da obra nietzschiana "Além do bem e do mal" afirmou que o pós modernismo tem preocupado em "ocultar piedosamente as afirmações de Nietzsche que poderiam ferir a sensibilidade demasiado delicada do homem contemporâneo" (p. 107). Admite que

O discurso nietzschiano sobre a mulher é complexo e problemático e possui arestas fartamente desagradáveis que a gente se sente imediatamente inclinado a silenciar. Não obstante, dificilmente poderia indicar-se uma obra de Nietzsche que não contenha um número considerável de observações sobre a mulher (MARESCA, 2001, p. 107).

Este artigo utiliza algumas das observações nietzschianas sobre as mulheres em um diálogo com a Genealogia da Moral produzida pelo autor. Considera que as formulações de Nietzsche acerca do tema da modernidade são extemporâneas, por isto perfeitamente compatíveis com nossa pós modernidade. Assim sendo, tenta-se compreender como a formulação de uma moral, ou seja, de um conjunto de normas e regras sociais que tem como propósito definir o que é uma mulher e como deve ser a sua conduta, desencadeou reações sociais opressivas, coercitivas, reguladoras e por vezes violentas contra as mulheres.

Das muitas formas de opressão, coerção e violência que se pode infligir às mulheres, toma-se por objeto a internação compulsória nos manicômios e a patologização de comportamentos afetivos e sexuais, como ocorrido de maneira mais amiúde durante o século XIX e meados do século XX no Ocidente, em particular no Brasil. A escolha de tal tema para se justifica em parte por se tratar de prática comum em um passado recente da história das mulheres. Cito também o fato de que os 
registros $^{2}$ que se têm de tais internações revelarem muitas inconsistências quanto aos motivos das mesmas e do fato de relatarem grande sofrimento imposto às mulheres encarceradas, como discorreremos mais adiante. Deste modo, as particularidades que atravessam muitos relatos de internações de mulheres em manicômios no Brasil deixam muitas indagações acerca do que pode levar familiares, cônjuges, médicos e outras profissões envolvidas, além das ciências médicas e psicológicas a endossarem as particularidades que envolveram tais internações.

Indagamos ainda sobre o que pode haver de mais profundo no campo social que possa ter permitido e mesmo endossado tantos casos de violação das liberdades e intensas crueldades com as mulheres? Estaremos nós mulheres libertas do jugo que outrora condenou nossos corpos e mentes ao encarceramento intramuros de onde não se podia escapar, a não ser sob a autorização de outrem? Fomos socialmente anistiadas dos pecados e das culpas que nos levaram ao destino que se tem o mais feroz dos animais - a clausura? Seria possível uma sociedade que nos tornasse isentas de novas violações de liberdade e violência moral, psíquica e física ou condenadas a gritar loucamente por nossos mais básicos direitos?

O recorte que aqui se utiliza tem enfoque em casos de mulheres internadas como forma de correção de uma postura diante da vida não condizente com os parâmetros sociais aceitáveis de moralidade. Mas de onde vem tais parâmetros de moralidade? Esta primeira pergunta pautará o início de nosso diálogo com Nietzsche. Consideramos importante frisar que buscaremos aqui antes a compreensão do pensamento do filósofo acerca de um modo de funcionamento social, para tanto não nos valeremos de uma sequência cronológica de seus escritos, mas sim de um esforço em encadear um pensamento verossímil.

\section{DESENVOLVIMENTO}

\subsection{A produção da moral social à luz do pensamento de Nietzsche}

\footnotetext{
${ }^{2}$ Os registros que tratam das internações de mulheres em manicômios no Brasil são o resultado de pesquisas do campo da História, do direito, do jornalismo e demais ciências sociais. Para este texto foram selecionados estudos publicados como livros, artigos e dissertações que tiveram como fonte de pesquisa os prontuários de instituições de internação manicomial, de onde foram retiradas as histórias de vida, da internação, da doença, a história familiar e social, os relatos do período de internação e dos tratamentos recebidos por estas mulheres durante o período em que estiveram reclusas nos hospícios ou manicômios.
} 
Grande parte da crítica de Nietzsche ao modo como a sociedade moderna se organizou é calcada na análise de como o ideal cristão tornou-se uma moral universal (críticas presentes na Genealogia da Moral; O Crepúsculo dos Ídolos; O Anticristo e outros.) e nos impactos que o ideal ascético provocou e ainda provoca na sociedade. Quando os povos adotaram o ideal cristão como verdade absoluta, parte das crenças em outros deuses, da potência que havia em seus rituais e na força da simbologia da vida e da renovação da natureza foram reduzidas a pequenos grupos. O cristianismo, ao pregar uma prática monoteísta, precisou fazer cair por chão toda a crença em outros deuses, e para isto utilizou-se de ideias como a de que há uma alma que habita nossos corpos e esta alma deve permanecer pura para garantir sua ascensão ao reino dos céus. O contrário disso é a condenação à danação da vida eterna no inferno, lugar de dores e sofrimentos indizíveis. Era preciso manter a vida gregária, “tornar o homem até certo ponto necessário, uniforme, igual entre iguais, constante, e portanto confiável [...] com a ajuda da moralidade do costume e da camisa-deforça social, o homem foi realmente tornado confiável” (Nietzsche, 1887, GM, II, \$2. 1998, pp.48 e 49).

Na terceira dissertação de Genealogia da Moral, Nietzsche faz a crítica às práticas sacerdotais embasadas no ideal ascético. Para o filósofo a ideia de práticas que visem apurar o espírito para garantir uma vida post mortem é uma ilusão prejudicial, uma forma de dominação que o cristianismo adotou para garantir sua sobrevivência. $\mathrm{Na}$ visão do autor, o ideal ascético, ao pretender o desenvolvimento espiritual, nega a única vida que conhecemos em detrimento de uma vida celestial que sequer sabemos existir. Nega o corpo ao valorizar o espírito, privando os indivíduos de uma existência mais potente e prazerosa; desprezando assim a própria vida e tornando fraco o desejo de viver, a potência que todo indivíduo tem de gozar da vida. Nas palavras do filósofo:

Uma vida ascética é uma contradição: aqui domina um ressentimento ímpar, aquele de um insaciado instinto e vontade de poder que deseja senhorear-se, não de algo da vida, mas da vida mesmo, de suas condições maiores, mais profundas e fundamentais; aqui se faz a tentativa de usar a força para estancar a fonte da força; aqui o olhar se volta rancoroso e pérfido, contra o florescimento fisiológico mesmo, em especial contra a sua expressão, a beleza, a alegria; enquanto se experimenta e se busca satisfação no malogro, na desventura, no fenecimento, no feio, na perda voluntária, na negação de si, autoflagelação e auto-sacrifício [SIC] (Nietzsche, 1887, GM, III, \$11. 1998, p. 107).

Apesar de o ideal ascético negar a vida, é como uma tentativa de preservar a própria vida que ele surge "o ideal ascético nasce do instinto de cura e proteção de uma vida que degenera, a qual busca manter-se 
por todos os meios, e luta por sua existência” (Nietzsche, 1887, GM, III, \$13. 1998 p. 109), expressa uma condição doentia a que o homem domesticado é lançado quando luta "com a morte (mais precisamente: com o desgosto da vida, com a exaustão, com o desejo do 'fim')" e o sacerdote ascético é a "encarnação do desejo de ser outro, de ser-estar em outro lugar", ou seja, no céu, uma vez que “o poder do seu desejo é o grilhão que o prende aqui”" (Nietzsche, 1887, GM, III, \$13. 1998, p. 110): seu desejo pela vida eterna é o que o faz suportar a vida terrena e o impele a guiar o seu rebanho, na esperança de merecer e garantir um lugar no paraíso.

Seu rebanho, por vez, é agrilhoado por vontade própria, e não por imposição forçosa. O sacerdote ascético, aparente inimigo e negador da vida, trava com os homens uma relação doentia que só é possível pois "o homem é mais doente, inseguro, inconstante, indeterminado que qualquer outro animal” (Nietzsche, 1887, GM, III, \$13. 1998, p. 110). Essa doença de que fala Nietzsche é a produção de um sujeito enfraquecido diante da vida e das suas vicissitudes, como aponta: "aqueles já de início desgraçados, vencidos, destroçados - são eles, são os mais fracos, os que mais corroem a vida entre os homens, os que mais perigosamente envenenam e questionam nossa confiança na vida, no homem, em nós” (Nietzsche, 1887, GM, III, \$14. 1998, p. 112). Nietzsche utiliza o termo ressentimento $^{3}$ ao referir-se a este auto envenenamento produzido pelos sentimentos dos fracos como a inveja, o rancor ou o ódio. Porém o homem fraco não é capaz de se vingar realmente da pressão, por isto vinga-se simbolicamente, crendo e fazendo crer que os fortes não são bons e não praticam o bem.

Interessa ressaltar que na apropriação feita por Nietzsche, quando o
ressentimento extrapola a mera descrição de uma fraqueza fisiológica, ele não se
caracteriza mais pela inação, como se tem no homem fraco e incapaz de reagir
frente às injúrias sofridas, mas, ao contrário, por uma forma de ação. No caso de
uma moral, por exemplo, mesmo em se tratando de uma forma de valorar que se
constitui a partir da fraqueza, ela se faz justamente para criar as condições
favoráveis para a expansão e predomínio desse homem fraco sobre os outros
tipos de homem. Nesses termos, embora postule uma negação do caráter
expansivo da vida, paradoxalmente, nas mãos dos impotentes, essa moral não

${ }^{3} \mathrm{O}$ ressentimento pode ser compreendido como um envenenamento que ocorre quando esses sentimentos não podem ser descarregados para fora e se voltam para o interior do homem, onde - não digeridos - ficam sendo resentidos. Um tipo de resposta apresentada frente a um estímulo externo que não é apenas sentido, mas res-sentido, ou que continua sendo sentindo mesmo quando ele já não existe mais, ao menos externamente, pois, internamente (no subterrâneo daquele homem) permanece produzindo seus efeitos.

Nesse organismo, a percepção da própria fraqueza e o sentimento de frustração que se segue à obstrução da ação gera um rancor, uma vontade de ferir e produzir sofrimento naquele que o detratou. Enfim, toma posse dele uma sede de efetuar aquela vingança que sua fraqueza não permite realizar (PASCHOAL, 2008, p. 14). 
deixa de ser uma forma de vida que pretende se expandir e se impor sobre as demais.

Assim, ao lado do ressentimento entendido como uma inibição da ação, tem-se também o ressentimento que designa uma vontade de poder operante (PASCHOAL, 2008, pp. 15 e16).

Compreende-se, portanto, que esse envenenamento produzido pelos sentimentos dos fracos ocorre, de acordo com o filósofo, tanto no âmbito individual quanto no social. O ressentimento enquanto fenômeno social é resultado de uma moral compartilhada, de uma moral elaborada pelo homem fraco ${ }^{4}$ que tem a intenção de tornar o homem forte um igual. No momento em que o fraco age elaborando uma moral que enfraquece o forte, ele se torna dominante, mas o domínio que ele exerce é redutível, rancoroso, até mesmo vingativo.

Paschoal afirma que o ressentimento social "não é propriamente fraco - embora tenha sua origem na fraqueza fisiológica e na rancorosa sede de vingança diante do 'inimigo mal' -, como Nietzsche descreve na primeira dissertação da Genealogia, em especial na seção nove" (PASCHOAL, 2008, pp. 21 e 22).

$\mathrm{O}$ argumento que o fraco utiliza para que a igualdade prevaleça no tecido social, fazendo do forte um fraco igual a si, é o sentimento de culpa nascido do ideal ascético cristão, como afirma no trecho: "O advento do Deus cristão, o deus máximo até agora alcançado, trouxe também ao mundo o máximo de sentimento de culpa” (Nietzsche, 1887, GM, II, \$20. 1998, p. 79). Este sentimento de culpa cristão gerou o que Nietzsche denominou de má consciência, que pode ser compreendida como uma moral gerada a partir do sentimento de culpa cristão, como pode ser compreendido nas palavras do filósofo na seção vinte e um:

[...] esse homem da má consciência se apoderou da suposição religiosa para levar seu automartírio à mais horrenda culminância. Uma dívida para com Deus: este pensamento tornou-se para ele um instrumento de suplício [...] seus autênticos insuprimíveis instintos animais, ele reinterpreta esses instintos como culpa em relação a Deus (Nietzsche, 1887, GM, II, \$22. 1998, p. 81).

\footnotetext{
${ }^{4} \mathrm{O}$ homem forte (nobre), para Nietzsche é aquele que tem coragem para ser honesto consigo mesmo e verdadeiro quanto aos seus desejos. Nas palavras do filósofo: "o homem nobre vive com confiança e franqueza diante de si mesmo [...] o homem do ressentimento não é franco, nem ingênuo, nem honesto e reto consigo. Sua alma olha de través; ele ama os refúgios, os subterfúgios, os caminhos ocultos, tudo escondido lhe agrada [...]" (Nietzsche, 1887, GM, I, §10. 1998, p. 29).
}

${ }^{5}$ Em referência à primeira dissertação da Genealogia da Moral de Nietzsche (1887, GM, I, §9. 1998, p. 28). 
Na segunda dissertação de Genealogia da Moral, Nietzsche critica a ideia de justiça enquanto "uma evolução do sentimento de estar-ferido - e depois promover, com a vingança, todos os afetos reativos" (Nietzsche, 1887, GM, II, \$11. 1998, p. 57), em referência à justiça pautada no ressentimento, que defende a reeducação e reinserção social, porém atua na aplicação de castigos, punições e cerceamento de liberdade como forma de correção. Nas palavras de Nietzsche, "a rebelião escrava na moral começa quando o próprio ressentimento se torna criador de valores: o ressentimento dos seres aos quais é negada a verdadeira reação, a dos atos, e que apenas por uma vingança imaginária obtêm reparação (Nietzsche, 1887, GM, I, \$10. 1998, p. 26)”.

Essa razão humana que cria valores morais e os torna universais foi, pois, uma elaboração feita pelos homens, mas não apenas para os homens. A moral que se tornou universal estendeu-se para toda a raça humana, de mulheres a crianças e idosos, todos tiveram que se sucumbir aos ditames sociais para que a vida gregária se tornasse possível. Leis, regras e normas comportamentais foram criadas com a finalidade de fazer funcionar o aglomerado humano que deixou para trás a vida nômade e se sedentarizou. Foi preciso esquecer a vida errante e deixar que se criasse uma nova memória que, nas palavras de Nietzsche levou à criação da razão:

[...] com a ajuda dessa espécie de memória chegou-se finalmente "à razão"! - Ah, a razão, a seriedade, o domínio sobre os afetos, toda essa coisa sombria que se chama reflexão, todos esses privilégios e adereços do homem: como foi alto o seu preço! Quanto sangue e quanto horror há no fundo de todas as "coisas boas"! ... (Nietzsche, 1887, GM, II, \$3. 1998, p. 52).

\subsection{As mulheres na modernidade e pós modernidade: uma interlocução com Nietzsche}

Conforme discutimos anteriormente, a obra de Nietzsche aborda inúmeras vezes a questão da mulher e elabora uma crítica acerca da ideia do que "é" ser "a mulher em si", dos ditames sociais que tronam-se universais e tendem a igualar os indivíduos, da adoção de uma pretensa verdade acerca do feminino que dita normas sobre como deve ser sua natureza (ou moral). Procurou, nas suas críticas, demonstrar que não é possível pensar ou descrever "a mulher", uma vez que essa 
unidade é inexistente, uma vez que as mulheres são distintas entre si, e possuem formas diversas de desejar, amar e viver ${ }^{6}$.

Em nosso entendimento, o filósofo destacou que as elaborações que tentam definir o que é "a mulher" são criações humanas e, uma vez que o homem é o protagonista da história do Ocidente, uma vez que são do homem as elaborações acerca das verdades científicas, dos sistemas de pensamento, das religiões e das normas morais adotadas, daí deduzimos que a mulher é também uma elaboração, uma criação do homem. Encontramos nos parágrafos 231 a 239 de Além do bem e do mal (ABM,1886), aquilo que consideramos serem afirmações inequívocas do pensamento do filósofo na qual apoiamos nossa afirmação de que a mulher é uma produção, uma criação do homem. Tomemos inicialmente o fragmento:

Certamente não faltam idiotas amigos das senhoras e corruptores da mulher entre os doutos jumentos masculinos, que aconselham a mulher a se desfeminilizar dessa maneira e imitar as estupidezes de que sofre o "homem" da Europa, a "masculinidade" europeia [...] e as tornam cada dia mais histéricas e mais incapacitadas para sua primeira e última ocupação, que é gerar filhos robustos. Querem "cultivá-las" ainda mais e, como dizem, através da cultura tornar forte o "sexo fraco": como se a história não ensinasse, do modo mais premente, que o "cultivo" do ser humano e o enfraquecimento - isto é, enfraquecimento, fragmentação, adoecimento da força de vontade - sempre andaram juntos, e que as mais poderosas e influentes mulheres do mundo (por último a mãe de Napoleão) deveram seu poder e autoridade junto aos homens à sua força de vontade - $\mathrm{e}$ não aos professores! (NIETZSCHE, ABM, 1888, \239. 1992, p. 145).

Ao atribuir aos "corruptores da mulher e doutos jumentos masculinos" a desfeminilização, entendemos que Nietzsche faz referência aos novos hábitos, principalmente entre a burguesia, de ocupar a mulher com questões como a vida social, as grandes recepções nos salões, a leitura de romances e poesias, como era prática da época. Porém, consumir tais escritos parece ser a única forma aceitável socialmente para as mulheres, pois a estas não era facultado o direito de criar e publicar romances, poemas, ensaios ou mesmo filosofia. O sem número de casos de mulheres que

\footnotetext{
${ }^{6}$ Quanto a este tópico, a Antropologia Cultural tem demonstrado a diversidade das culturas em todo o mundo. Os valores, as formas de relacionamentos conjugais, de se viver em sociedade, as crenças religiosas, etc. tudo isto é bastante diverso. Sendo assim, é razoável entender que também a forma como as mulheres pensam e se colocam na vida gregária acompanha esse ethos local. Se uma determinada moral é adotada como sendo a mais adequada às mulheres, torna-se esperado que seja adotada por elas, passando então à condição de universalidade nos modos de viver, pensar, sentir e agir das mulheres daquele grupo.
} 
escreveram e publicaram sob pseudônimo masculino ${ }^{7}$ ou mesmo de forma anônima ${ }^{8}$ confirmam o lugar de mera consumidora que era autorizado às mulheres.

Ainda no parágrafo supracitado, vislumbramos que no trecho "as tornam cada dia mais histéricas e mais incapacitadas para sua primeira e última ocupação, que é gerar filhos robustos”, o termo "histéricas" faz referência a uma classificação nosológica utilizada ainda na atualidade. Não se sabe certamente quando surgiu a ideia de uma doença, um distúrbio próprio das mulheres, mas há registros de papiros médicos datados de 1900 e de 1500 A.C. que já descreviam "distúrbios somáticos, ou do comportamento, observados em mulheres" (VILLARI, 2001, p. 132). Na Antiguidade, Hipócrates, considerado o pai da medicina, descreve um distúrbio ligado ao útero que denominou globus hystericus, em uma alusão a uma bola, o útero, que se deslocava pelo corpo das mulheres e causava as mais diversas condições patológicas e sintomas variados (VILLARI, 2001, p. 133). Durante a Idade Média, sintomas de alucinação foram reconhecidos como casos de possessão demoníaca, levando uma cruzada contra os considerados hereges, ou seja, aqueles com comportamentos comprovadamente "desviantes" eram condenados à morte por enforcamento, afogamento ou queimados nas fogueiras. As mulheres, sobretudo quando não cumpriam os papéis sociais esperados, eram consideradas bruxas e tinham o destino de todos os demais desviantes (DELUMEAU, 2009).

A crença em uma patologia tipicamente feminina tinha em comum, em todas essas épocas, que o útero (bystero em latim, de onde deriva o nome histeria) se deslocava e circulava pelo corpo das mulheres que apresentavam distúrbios relacionados à abstinência do ato sexual fálico, ou seja, heterossexual. Freud (1888-s/d), após dois mil anos ainda utilizou a terminologia cunhada por Hipócrates para descrever uma espécie de bola que subia pelo corpo até a garganta. Munido da ideia de que mulheres com privação da sexualidade normativa (heterossexual) desenvolveriam distúrbios nervosos e psíquicos próprios, Freud estabeleceu as bases do pensamento psicanalítico acerca da sexualidade feminina pautada no desejo pelo falo, o objeto faltante na mulher que, ao descobrir-se alijada do mesmo, passaria a sofrer de uma ansiedade doentia que só cessaria ao

\footnotetext{
${ }^{7}$ Um dos exemplos mais conhecidos é o caso das irmãs Brontë, inglesas do século XIX, que publicavam suas obras com pseudônimos masculinos para driblar a moral da época que não aceitava publicações femininas. Trata-se de Charlotte Brontë (pseudônimo de Currer Bell), escritora de "Jane Eyre" e outras obras. Emily Brontë pseudônimo de Ellis Bell), escritora de "Wuthering Heigts" e outras obras; e Anne Brontë (pseudônimo Acton Bell), escritora de The "Tenant of Wildfell Hall" e outras obras.

${ }^{8}$ Outro exemplo inglês do século XIX é a escritora romancista Jane Austen, que publicou suas obras de forma anônima e cujas publicações eram negociadas com as editoras por seus irmãos. Escreveu romances que fizeram grande sucesso e ainda hoje são lidos e estudados, como "Sense and Sensibility" (1811) e "Pride and Prejudice" (1813) dentre outros.
} 
adquirir, por meio do ato sexual, um falo. Fundada a base da psicanálise feminina calcada na ideia do desejo pelo falo e na histeria quando tal desejo não se realizava, coube à medicina, em especial à psiquiatria, que adotando a concepção de distúrbio tipicamente feminino vinculado ao útero e às insatisfações sexuais ocasionadas por abstinência ou por excessos, a converteu em uma patologia de fundo psíquico (neurológico e comportamental). Deixando de ter o caráter de uma condição abstrata atribuída às mulheres, a histeria tornou-se patologia neuropsíquica amplamente utilizada para diagnosticar mulheres nos séculos XIX e XX no Ocidente (VILLARI, 2001).

Em nosso entendimento, o argumento expresso por Nietzsche (ABM, 1888, \ 239. 1992, p. 145) no fragmento anteriormente citado, de que os homens tornam as mulheres mais histéricas', denuncia a disseminação da ideia de que a mulher sexualmente frustrada, presa a um modelo de sexualidade só aceita e concebida dentro de um único modelo estabelecido social e moralmente o sexo normativo (heterossexual), fálico e restrito ao casamento monogâmico -, se tornaria doente e incapaz. A falta do falo adoeceria a mulher. Vemos, em outro excerto do mesmo parágrafo: “como se a história não ensinasse, do modo mais premente, que o ‘cultivo’ do ser humano e o enfraquecimento - isto é, enfraquecimento, fragmentação, adoecimento da força de vontade - sempre andaram juntos" (NIETZSCHE, ABM, 1888, \$ 239. 1992, p. 145), um reforço no nosso argumento de que os hábitos, as verdades científicas, religiosas e os costumes da época, ou seja, o "cultivo" da mulher gerava o seu enfraquecimento, fazendo dela o sexo frágil que deve ser cuidado pelo homem, uma vez que, vulnerável, é alçada à condição de ser incapaz de cuidar de si mesma. Segundo este entendimento, esta precariedade da capacidade do auto cuidado condiciona a mulher à obediência ao homem, que é por excelência o cuidador e provedor. Por isto a mulher deve ser submissa ao homem, condição que a inferioriza.

Ideia a ser combatida por entendermos que as mulheres sabem como cuidar de si, ou ao menos devem gozar da oportunidade de fazê-lo. Ao lermos no trecho: "as mais poderosas e influentes mulheres do mundo [...] deveram seu poder e autoridade junto aos homens à sua força de vontade - e não aos professores!” (NIETZSCHE, ABM, 1888, \239. 1992, p. 145) concebemos que as mulheres são perfeitamente capazes de cuidar e dizer verdades sobre si, de elaborar e criar modos de vida que lhe serão mais aprazíveis, desde que sejam capazes de prescindir dos professores, os homens que as precedem nas verdades a elas atribuídas.

No parágrafo anterior (NIETZSCHE, ABM, 1888, \238. 1992, p. 143), a afirmação de que “equivocar-se no problema fundamental 'homem e mulher', nele negar o mais profundo

\footnotetext{
${ }^{9}$ Quando Nietzsche publicou tal escrito (ABM, 1888), Freud publicava os resultados de seus estudos clínicos com as mulheres histéricas.
} 
antagonismo e a necessidade de uma tensão hostil, e sonhar talvez com direitos iguais, igual educação, reivindicações e deveres iguais: eis um sinal típico de superficialidade", nos remete a um argumento de que diferenças entre homens e mulheres existem, e o fato de as mulheres terem em si o dom de gerar filhos, de tornar-se prenhe de outra vida humana, por si já deveria ser argumento socialmente aceitável e adotado para pensar a questão do "profundo antagonismo" que existe entre os dois gêneros.

Entendemos que sendo as mulheres as geradoras da vida, o reconhecimento desse antagonismo entre os gêneros masculino e feminino poderia levar ao reconhecimento da necessidade de condições adequadas para que aquelas mulheres que optarem pela maternidade possam cuidar dos seus filhos, oportunizando às mesmas circunstâncias mais condizentes à importância da tarefa de gestar e zelar das gerações futuras. Porém, ainda sobre a reverberação da moral criada pelos homens, as mulheres travam suas lutas em busca de igualdade, prescindindo, muitas vezes, das suas necessidades.

Lopes (2018, p.41) pondera que, apesar de toda a luta das mulheres por igualdade de direitos e deveres, "a ampliação dos lugares autorizados para o trabalho das mulheres (fábricas, comércios, instituições de ensino e de saúde, instituições do poder político etc.) não necessariamente significou qualquer obtenção e/ou extensão do poder delas”. Ou seja, permanecemos sobrecarregadas pelo acúmulo de funções sociais, obrigações domésticas, familiares, trabalhistas e ainda geramos, parimos, cuidamos e criamos os filhos que sucederão as gerações, mantendo a linhagem humana no mundo. Sobre tal questão, Lopes escreve:

A despeito de tudo que pode ser considerado avançado nas sociedades contemporâneas, não restam quaisquer experiências de poder que sejam mobilizadas pelo poder dos corpos das fêmeas humanas de gestar, parir e amamentar vidas, ou mesmo de interromperem nascimentos, apesar de todo o histórico das mulheres de serem capazes tanto de engravidar como de se apropriarem dos saberes sobre o aborto (LOPES, 2018, p.45).

Desse modo, entendemos que desejar e lutar por igualdade de direitos e de deveres pode enfraquecer e inferiorizar a mulher, torna-la submissa aos ditames sociais que, por sua vez, fazem com que as conquistas resultantes de tais lutas, como a maior participação na vida social, o direito ao voto, a ampliação dos espaços para o trabalho, reduzam os corpos femininos ao utilitarismo da produção de mercadorias e produtos e ao consumo destes (LOPES, 2018). Ao pensarmos sobre essa condição a que as mulheres estão submetidas, é preciso considerar que os processos formativos, ou seja, as subjetividades são calcadas no campo social, em contato com os costumes, 
hábitos, normas e regras vigentes. Sendo assim, algo que é considerado como real, autêntico ou certo tende a ser adotado como verdade universal e passa a ser reproduzido socialmente. Desse modo, pode-se compreender que as mulheres, por se subjetivarem em um meio social heteronormativo e de supremacia masculina, tendem a adotar como seus os dogmas coletivos elaborados pelos homens, e por vezes lutam por estes e até os defende. Nesse sentido, entendemos que é a estas condições de subjetivação e de modo de entender o mundo a que o trecho abaixo se refere ao afirmar que "a mulher", essa criação masculina aceita e adotada como sendo "a mulher em si"

[...] não quer a verdade: que interessa à mulher a verdade! desde o início nada é mais alheio, mais avesso, mais hostil à mulher que a verdade - sua grande arte é a mentira, seu maior interesse, a aparência e a beleza. Vamos confessá-

lo, nós, homens: nós festejamos e amamos precisamente essa arte e esse instinto na mulher: nós, para quem as coisas são pesadas e que de bom grado nos juntamos, para obter alívio, a seres cujas mãos, olhares e ternas tolices nos fazem parecer quase tolice a nossa seriedade, nosso peso e profundidade (NIETZSCHE, ABM, \232.1992, p. 140).

Uma crítica à situação de enfraquecimento a que as mulheres estão submetidas e que as incapacita para perceber, devido à sua subjetivação, que sua condição gera conforto aos homens, faz com que se acomodem e usufruam do gozo que tal conjuntura lhes proporciona. Desse modo, os homens não desejam que mudanças ocorram e que as mulheres tenham possibilidade de elaborar-se a si mesmas. Em outro fragmento Nietzsche escreve: "com tudo o que as mulheres escreveram sobre 'a mulher', é lícito duvidar que a mulher queira ou possa querer esclarecimento sobre si..." (NIETZSCHE, ABM, 1886, \232. 1992, p. 140). Reconhecemos em ambas as passagens que o filósofo faz alusão a essa mulher criada pelo homem, às verdades elaboradas pela mulher e das quais a própria mulher se apropria como sendo sua, as acolhe, as transmite às suas descendentes como se suas fossem.

Ao afirmar que a mulher não quer saber a verdade sobre si, Nietzsche deixa dúvidas sobre como se procede esse "não-querer": se não se quer por não ter coragem de conhecer; não se quer por não ser capaz de perceber, uma vez que o próprio filósofo diz da sutileza, da natureza rasteira do ressentimento daqueles que elaboram as normas sociais. Nesse caso, ela não pode perceber pois se vê impossibilitada devido à natureza enigmática e indireta daquilo que toma por si. Ainda há a possibilidade de "não poder" conhecer a verdade sobre si dada a relação de obediência a que está submetida e à própria condição de posse masculina em que muitas vezes ela é colocada. Ainda há 
a perspectiva de que a mulher simplesmente não deseja conhecer a verdade sobre si mesma, uma vez que o lugar que ocupa lhe é conveniente.

Adotamos a concepção de que "querer" ou "poder" exprime que as mulheres não percebem que a vOz que delas diz verdades e para elas estabelece normas, não é a voz da própria mulher, mas sim a do homem. As mulheres não conhecem a verdade sobre si mesmas e nem sempre é dado a ela a possibilidade de elaborar uma verdade que seja sua, tarefa que só seria possível no debruçar-se sobre si, no criar a si mesmas; no exercício de tornar-se o que se é, de gestar e parir o próprio espírito. Porém, elaborar-se a si mesmo não é tarefa simples, como entendemos ao lermos o aforismo 339 de "A Gaia Ciência", intitulado

Vita Femina [A vida é uma mulher]. - Para ver a beleza última de uma obra não bastam todo o saber e toda a disposição; os mais raros e felizes acasos são necessários, para que o véu de nuvens se afaste uma vez desses cumes e nós os vejamos refulgir ao sol. Não apenas devemos estar no lugar certo para presenciar isso: nossa alma teve de arrancar ela própria o véu de suas alturas e necessitar de uma expressão e símbolo exterior, como que para ter um ponto de apoio e continuar senhora de si. Mas é tão raro que tudo isto suceda ao mesmo tempo, que me inclino a crer que as maiores alturas de tudo o que é bom, seja de uma obra, um ato, a humanidade, a natureza, permaneceram algo oculto e velado para a maioria e mesmo para os melhores dos seres humanos até hoje [...]. Mas talvez esteja nisso o mais forte encanto da vida: há sobre ela, entretecido de ouro, um véu de belas possibilidades, cheio de promessa, resistência, pudor, desdém, compaixão, sedução [...] (NIETZSCHE, 1882, GC, I - V, II, 59, Vita Femina 2012, pp. 203 - 204).

A referência a obra enquanto construção de si está presente na obra de Nietzsche em várias passagens, assim como utiliza o termo gravidez em referência ao período de elaboração de si e parir filhos como metáfora para a obra dessa elaboração. A tarefa da elaboração de si não é fácil dadas ao estilo de vida da modernidade e pós modernidade, em que foram adotados princípios tomados como universais, que tendem a uniformizar os modos de ser, pensar e agir das comunidades. Os preceitos sociais criam a necessidade de prestação de contas das ações individuais, das palavras proferidas e por vezes até dos pensamentos, caso das práticas confessionais adotadas por algumas religiões ou mesmo pelas ciências que propõe terapias da mente e conduz os sujeitos às confissões de seus mais íntimos pecados aos médicos, psiquiatras ou mesmo os psicólogos.

Reconhecemos ainda nestas passagens de Nietzsche: "existem locuções e lances do espírito, existem sentenças, um punhado de palavras, em que toda uma cultura, toda uma sociedade se cristaliza de repente" (NIETZSCHE, ABM, \235, p. 141) e mais adiante, no $\ 237$ a (ABM, $\ 237 \mathrm{a}$, p. 143, onde afirma que "até agora os homens trataram as mulheres como pássaros que lhes 
tivessem caído das alturas: como algo mais delicado, mais vulnerável, mais doce, selvagem, exótico e cheio de alma - mas como algo que se prende, para que não fuja voando”, a condição satisfatória e cômoda em que os homens se veem com relação à condição social das mulheres, alçadas a propriedade privada dos seus pais, irmãos e posteriormente maridos.

Devido aos costumes atribuídos às mulheres, estas tornam-se devedoras de obrigações para com os homens de sua linhagem, para com os homens com os quais envolve-se afetivamente, para com os filhos, a igreja, a família, o trabalho, a sociedade. Tornam-se também devedoras de seus corpos, que não podem envelhecer e perder a formosura da adolescência; devedoras das obrigações domésticas e do trabalho remunerado. Sentem-se culpadas quando estão extenuadas, exaustas, desgastadas. Mais culpadas ainda quando decidem que esta não é a melhor opção para si e deseja se arriscar e criar outra possibilidade de vida. Estas são as condições em que encontram-se as mulheres sobre as quais iremos dialogar.

Deste modo, após apontarmos nossa leitura de como Nietzsche pensou uma sociedade capaz de adotar uma moral unívoca e agir de modo vingativo, punitivo e excludente para com todo aquele que se recusar a seguir a norma moral determinada, torna-se possível examinar as histórias sobre o encarceramento de mulheres em hospícios no Brasil, como forma de punição ou correção para aquelas consideradas desviantes da norma vigente e por isto, loucas e perigosas, tanto para seus familiares e para a sociedade quanto para si mesmas, uma vez que são capazes de escolher uma vida errante em detrimento da sagrada família; de abandonar os filhos e o lar para viver de acordo com seu desejo; de dedicar-se exclusivamente ao trabalho intelectual em detrimento de tornaremse belas, educadas e meigas, como quer o paradigma social vigente.

\subsection{Mulheres no manicômio: pensar com Nietzsche}

Tomamos nosso primeiro caso para discutir a relação da mulher com o encarceramento compulsório em manicômios no Brasil, trechos da história narrada pela jornalista Arbex (2013) no livro intitulado Holocausto Brasileiro, que retrata em texto, fotografias, depoimentos e documentos (prontuários de pacientes), os horrores do Hospital Colônia na cidade mineira de Barbacena, durante cinco décadas do século XX. Dentre as denúncias de Arbex, algumas muito graves, estão as internações sem consentimento ou mesmo sem o conhecimento dos pacientes; pessoas que viveram no internato desde o nascimento ou a infância; pacientes que morriam de fome, frio, maus tratos, etc. e uma infinidade de variações de maus tratos, os quais ela classificou como formas de 
tortura: internos nus mesmo durante o inverno para a economia de roupas e da lavagem das mesmas; internos dormindo em colchões de capim seco e em camas feitas do mesmo capim no chão, com o objetivo de caber mais pessoas em um único alojamento; internos explorados em trabalhos forçados, bebendo água de esgoto e comendo até ratos para amenizar a fome; sujos de fezes; recebendo castigos variados, dentre eles o eletrochoque como punição para mau comportamento, etc.

Dos registros publicados por Arbex sobre este hospital psiquiátrico extraímos seguinte história:

Aos quinze anos, Conceição foi mandada para o hospital, porque decidiu reivindicar do pai a mesma remuneração paga aos filhos machos. Embora trabalhasse como os irmãos na fazenda de Dores do Indaiá, município pouco povoado do centro-oeste das Gerais, a filha do fazendeiro não desfrutava dos mesmos direitos. Pela atitude de rebeldia da adolescente, o pai aplicou o castigo. Decidiu colocar Conceição no famigerado "trem de doido"10, único no país que fazia viagens sem volta. Em 10 de maio de 1942, ela deu entrada no hospital, de onde nunca mais saiu. Em trinta anos, nunca recebeu visita.

No começo, a filha de Indaiá foi tomada pela indignação. Bonita, jovem e lúcida, não aceitava o diagnóstico de loucura. Por isso, agredia os guardas, desafiava com violência a ordem imposta. $\mathrm{O}$ peso da retaliação era maior do que a ousadia da adolescente. Como castigo, Conceição passou mais de dois anos trancada em cela inferior a dez metros quadrados. Só via a luz do sol vinte minutos por dia. Lutou com todas as suas forças para não se envergar diante do peso da sentença até decidir canalizar sua energia para tentar mudar o lugar que passou a ser seu mundo. Levantou a vOZ para exigir médicos, alimentação de qualidade, assistência digna, tornando-se líder de seu grupo (ARBEX, 2013, p.p. 40-42).

A história de Conceição nos leva à questão do ressentimento social que modula normas sociais e leis em forma de uma justiça punitiva, vingativa, e não uma justiça educativa, cuja pretensão seria a de ajudar os sujeitos a encontrarem outros modos de resolução de seus conflitos diferentes daqueles com caráter criminoso.

A relação familiar calcada no modelo tradicional (patriarcal) em que a autoridade é centrada na figura masculina, somada às ideias de submissão feminina, da obrigação da obediência devido à condição de fragilidade e incapacidade para o auto cuidado atribuído à mulher, logo se tornou autoritarismo nas ações praticadas pelo pai. Note-se que não há relato de que Conceição era órfã de mãe. No entanto não há registro de que ela tenha recebido a visita de nenhum dos seus familiares durante todo restante da sua vida (o que pode apontar para uma postura extremamente autoritária de seu progenitor), que aliás, se deu dentro do Colônia.

${ }^{10}$ Trem de doido é como ficou conhecido o trem que transportava os pacientes para o Hospital Colônia. 
A inferioridade com que Conceição era vista pela família a colocou em outra condição: a de propriedade do pai, que, entendendo ser possuidor de plenos direitos sobre sua vida e seu corpo, sentiu-se livre para explorar seu trabalho sem se ocupar com sua remuneração, apesar de remunerar os irmãos "varões". Indignado ao ser questionado em sua autoridade de senhor soberano de direito sobre o corpo e a vida de Conceição, a exemplo dos reis absolutistas, seu progenitor decide se vingar e encarcera a adolescente pelo resto de sua vida.

O que endossou tamanha atrocidade? O pátrio poder, o direito que os pais tinham de decidir por seus filhos menores de idade e por suas filhas solteiras em qualquer idade. A justiça aliada à medicina, que frente à desobediência da filha, à sua impertinência de questionar a autoridade do pai, pode exercer o seu poder de ciência que diz do sujeito uma verdade: Conceição era louca! Diagnóstico de loucura baseado na sua desobediência? $\mathrm{Na}$ insubordinação? $\mathrm{Na}$ insurreição contra sua condição de inferioridade diante das obrigações trabalhistas na fazenda?

Assim como Conceição, encontramos outras histórias de mulheres internadas por seus familiares por não concordarem com suas atitudes frente a um desejo de emancipação, de tomada do poder de decidir sobre a sua própria vida. Como no caso relatado por Vacaro (2001) extraído do prontuário de E.C., internada no Sanatório Pinel de Pirituba - SP por solicitação de seus irmãos, que discordavam do modo como havia decidido conduzir a sua vida. Aos 50 anos, solteira e professora, E.C. é descrita no prontuário como

Muito inteligente, recebia os maiores elogios na Escola Normal onde estudou. Trabalhava demais; havia uma hiperexcitação intelectual. Escrevia livros escolares que julgava modelos; fundava escolas noturnas, comprava livros e livros para ler. Já neste tempo, tornava-se totalmente independente; não admitia intervenção ou conselho dos pais ou irmãos mais velhos; confiava exclusivamente em si. Teve dois abalos morais por casamentos rompidos. Foi sucessivamente brigando com todos os irmãos; tornou-se agressiva mesmo com os próprios pais e quase que repentinamente caiu em pura excitação maníaca (VACARO, 2001, p. 29).

Dentre outros motivos alegados pela família para a sua internação, constava a insatisfação com os sucessivos casamentos, além, é claro, da "excessiva independência" e dedicação ao trabalho e aos estudos, "coisa anormal para uma mulher!". Vacaro (2001) não informa os desdobramentos da internação compulsória de E.C., portanto não é possível precisar por quanto tempo ela se viu privada de sua liberdade. Em comum, Conceição e E.C. possuem o desejo da independência e a imposição de um modelo de feminilidade normativa do qual, qualquer estratégia de vida que desviasse implicaria na necessidade de recondução ao seu lugar. As resistências eram punidas de 
forma severa, como no caso de Conceição, que resistiu ao diagnóstico, rebelou-se, tentou de muitas formas livrar-se do jugo daquela internação e, ao perceber a impossibilidade dessa ação, reorganizou-se para tornar o lugar onde viveu seus dias ao menos mais tolerável.

Entendemos que Nietzsche, ao discutir a justiça pautada no ressentimento, a justiça como uma prática punitiva, colocou em questão a relação dos castigos aplicados pelos pais a seus filhos, como no excerto abaixo em que demonstra que o castigo como punição, e não com intenção de correção ou ensinamento, é prática utilizada desde o homem primitivo, como segue:

Durante o mais largo período da história humana, não se castigou porque se responsabilizava o delinquente por seu ato, ou seja, não pelo pressuposto de que apenas o culpado devia ser castigado - e sim como ainda hoje os pais castigam seus filhos, por raiva devida a um dano sofrido, raiva que se desafoga em quem o causou (NIETZSCHE, 1887, GM, II, \$4.1998, p. 53).

O castigo pautado pela raiva não adquire características de correção do erro cometido ou ensinamento de que não se deve cometer tais atitudes, mas sim de vingança. Portanto, não há desejo de reparo de um dano cometido, mas sim a vazão do ressentimento, do ódio e da raiva. Quando se acredita que uma mulher feriu uma norma social, o sentimento de raiva e vingança tentem a tomar proporções maiores e as interdições e ações coercitivas tendem a ser extremas, como nos casos narrados. Considerando que o julgamento das atitudes femininas tendem a ser na medida do entendimento daqueles com quem elas convivem, como seus pais, companheiros, etc., o resultado pode ser o alto índice de violência contra a mulher registrados atualmente em grande parte do mundo, como no Brasil. Nota-se um elevado índice de homicídios, em uma espécie de crime cometido em relação ao gênero feminino, o feminicídio: mata-se por ser mulher; por esta ter se recusado a obedecer, a cumprir o papel que a sociedade atribui às mulheres; mata-se pelo simples fato de ser uma mulher ${ }^{11}$. Registre-se também o fato de que a maioria dos casos de violência contra a mulher acontece no ambiente familiar, lugar onde o pátrio poder é exercido e o homem, tradicionalmente, é autoridade. Em relação à obediência exigida das mulheres, Nietzsche escreve:

[...] um homem que tenha profundidade tanto no espírito como nos desejos, e também a profundidade da benevolência que é capaz de rigor e dureza, e é confundida facilmente com estes, não pode pensar sobre a mulher senão de modo oriental - ele tem de conceber a mulher como posse, como propriedade a

\footnotetext{
${ }^{11}$ Observa-se nesse quesito os inúmeros casos de homicídio após estupro, em que as vítimas mulheres são assassinadas após serem violentadas sexualmente.
} 
manter sob sete chaves, como algo destinado a servir e que só então se realiza [...] (NIETZSCHE, ABM, \238, p. 143).

Em nossa leitura, o homem descrito por Nietzsche no trecho acima é o homem ressentido, o animal de rebanho que adota para si as normas sociais que ele elabora e propaga como verdades, sob as quais se vive sem muita reflexão ou resistência. Esse homem tende a compreender a mulher em concordância com o que dita o ideal ascético: a mulher é propriedade do homem e a ele deve obediência. Ao referir-se ao homem como aquele que tem a "profundidade da benevolência que é capaz de rigor e dureza", entendemos que se trata do homem de religião, aquele que aprende com esta a má consciência, a culpa e a necessidade de ser bom como forma de garantir o seu lugar na outra vida - o homem do rebanho, obediente ao ideal ascético.

Para este homem, toda a verdade sobre a mulher está nas sagradas escrituras: ela foi criada por Deus para ao homem pertencer, e a ele pertence para que dela faça o que for para a manutenção da justiça, da bondade e da garantia da vida gregária. A bondade que conhece está restrita àquilo que lhe garanta segurança e perpetue seu poder, que não permita que seja inferiorizado diante da mulher que lhe foi dada por Deus, portanto, sua propriedade para usufruir e dispor como desejar.

Nietzsche ao fazer a crítica do ideal ascético, da justiça praticada como vingança e punição, da moral tornada universal e da qualidade sub-reptícia da moral ressentida escreveu:

Olhe-se o interior de cada família, de cada corporação, de cada comunidade: em toda parte a luta dos enfermos contra os sãos - uma luta quase sempre silenciosa, com pequenos venenos, com agulhadas, com astuciosa mímica de mártir (NIETZSCHE, 1887, GM, III, \$14. 1998, p.113).

Nesta passagem, os enfermos são os ressentidos e os sãos, os fortes; aqueles capazes de se auto analisar, de buscarem alternativas de vida diversas daquela imposta pela moral. Importante ressaltar que a relação entre fortes e fracos não é algo determinado, mas sim é algo que pode ser mobilizado, ou seja, em determinadas circunstâncias pode-se tornar fraco e em outras, fraco. Ser fraco ou forte não é condição imutável, mas sim um estado que se movimenta de acordo com as modificações que os sujeitos vivenciam em decorrência dos afetos com os quais entram em contato.

Percebemos no trecho supracitado que a moral, ao se alastrar por todo o campo social, torna-se universal, adentra as famílias, corporações, comunidades, instituições, escolas, etc. e desse modo se define o que passa a ser o "papel da mulher", do qual ela não pode fugir sob pena de ser submetida 
à correção dos desvios. Como ocorrido no caso de Elza relatado por Muñoz (2010) e que discutiremos na sequência.

Elza era uma alemã que veio para o Brasil após a Primeira Guerra Mundial, em companhia de seu marido, o também alemão Gustav. Passado algum tempo desde sua chegada, entre muitos encontros, conflitos e desencontros, Elza decidiu se separar de Gustav e se abrigou em casa de amigos.

Gustav, inconformado, foi ao seu encontro e tentou convencê-la, de diversas formas, a regressar ao lar. Decidida, Elza se recusou. Gustav então, exercendo o seu direito de marido, recorreu à polícia e solicitou a internação compulsória de Elza, que foi prontamente recolhida no Pavilhão de Observação do Hospital Nacional de Alienados na cidade do Rio de Janeiro, onde viva. Elza foi conduzida pela polícia, o que Muñoz (2010) relata ser prática na época, ou seja, cabia à polícia recolher os pacientes a serem enviados aos sanatórios e afins. Elza, mostrando toda a sua indignação, recusou-se a falar com a equipe médica e seu histórico e sintomas foram produzidos a partir dos relatos de seu ex marido Gustav. Desse relato rendeu a Elza o diagnóstico de "estado atípico de degeneração, sindrome paranóide de interpretação e delírio de ciúmes", o que a colocava como uma mulher intelectualmente incapaz e doente de excesso de amor.

A imprensa local tomou conhecimento do caso e procurou Gustav, que começou a dar declarações públicas e acusar Elza de tê-lo traído com seu sócio. Indignada, Elza decidiu, por sua vez, contar toda a história que até o momento havia calado: Gustav era violento, abusivo e possessivo, além de haver tido vários casos extraconjugais, eis o motivo que a levou a sair de casa e desejar a separação. As declarações de Elza não bastaram à polícia, nem à justiça e nem aos médicos. Foram necessárias várias testemunhas que confirmaram os relatos de Elza e um Habeas Corpus impetrado na justiça para garantir sua soltura. Inconformado, Gustav tentou novamente internar Elza, dessa vez sem êxito.

Muitos casos semelhantes ao de Elza estão descritos na literatura que trata das internações de mulheres em manicômios. Casos de mulheres que, esgotadas e exauridas da condição de vida que levavam ao lado de seus maridos, decidiram sair de casa e recomeçar suas vidas. Porém, como a mulher era (e ainda é) vista como propriedade do homem, eram enviadas aos manicômios como forma de correção. No caso de Elza e de tantas outras, o marido ainda desejava viver com a mulher, desde que esta se adequasse às normas e aos seus caprichos de macho dominante. Mas há também relatos de muitos outros casos de mulheres internadas porque seus maridos não mais desejavam viver com elas, e a internação era uma forma de livrar-se do compromisso. 
Cabe entender que terminar um casamento alegando que a mulher ficou louca e incapaz, por vezes perigosa para a casa e os filhos pode ser uma saída bastante conveniente para um homem que deseja recomeçar a sua vida. A ele nenhuma culpa, nenhum desvio, nenhuma mancha ou desabono na reputação de homem de bem. A mulher toda a carga do abandono, a retirada da vida social e familiar, a separação dos filhos e uma vida presa entre doentes e incapazes de todas as espécies. Ao homem que pratica tais atos a liberdade para um recomeço. A mulher a punição pela falta de amor.

Porém, como o entendimento sobre a loucura feminina era e permanece sendo diferente do entendimento sobre a loucura masculina, como aponta Engel (2004), às mulheres nunca foi facultado o direito de interditar seus maridos por interesses outros que não o da comprovada incapacidade psíquica. Ocorre que a loucura feminina, ainda hoje, é pautada na sexualidade, no comportamento social, doméstico e no cumprimento do "papel feminino", em detrimento de uma avaliação mais objetiva da condição psíquica, em que pontos com mais destaque para o diagnóstico estejam relacionados a estar ou não aptas a desenvolver suas atividades laborais e cuidados pessoais, como apontado por Engel (2004).

Diante dessas diferenças e de toda opressão sofrida pelas mulheres nas relações conjugais e familiares, encontramos ainda relatos de mulheres que solicitaram sua internação para ter algum descanso e se ver desobrigada de tanta satisfação a dar e tantas obrigações sociais a cumprir (VOCARO, 2011). Outros registros ainda dão conta do desespero que toma conta de muitas mulheres que acabam por cometer crimes contra seus maridos agressores e abusivos, como única forma encontrada para se verem livres do jugo imposto e do qual não encontraram forma de sair. O fato de não se mostrarem arrependidas com o crime cometido é suficiente para que sejam consideradas incapazes do convívio social e por isto condenadas ao perpétuo encarceramento em um manicômio judicial, como demonstrado nos trabalhos de Miranda e Popperl (2019), Miranda (2016) e Oliveira (2019).

Retomemos novamente o caso Elza para pensar a questão do envolvimento da polícia na sua apreensão e condução coercitiva até a internação compulsória no manicômio, por ordem de seu marido, e sem ao menos ouvi-la antes. Já demonstramos que Nietzsche aponta como as instituições se tornam parte do mecanismo de funcionamento da moral unívoca (Nietzsche, 1887, GM, III, \$14. 1998, p.113) e o caso de Elza é um exemplo de como se dá essa colaboração, esse envolvimento. Tanto a polícia, quanto à justiça, quanto a medicina agiram pautados pelos relatos e desejos de seu marido. Apresaram-se em cumprir suas ordens e tentar restabelecer a ordem social, garantindo que sua mulher, portanto sua propriedade, não lhe escapasse.

Observemos o trecho em que Nietzsche escreve: 
Eles rondam entre nós como censuras vivas, como advertências dirigidas a nós - como se saúde, boa constituição, força, orgulho, sentimento de força fossem em si coisas viciosas, as quais um dia se devesse pagar, e pagar amargamente: oh, como eles mesmos estão no fundo dispostos a fazer pagar, como anseiam ser carrascos! Entre eles encontram-se em abundância os vingativos mascarados de juízes [...] entre eles não faltam igualmente a mais nojenta espécie de vaidosos, os monstros de mentalidade que buscam aparecer como "almas belas" (Nietzsche, 1887, GM, III, \$14. 1998, pp. 112 e113).

Novamente entendemos que Nietzsche trata do homem de ressentimento, do animal de rebanho que age para garantir a igualdade entre os sujeitos. E reitera o desejo de vingança para com aquele ou aquela que ousar desejar encontrar em si a potência da vida, descritas no trecho como "saúde, boa constituição, força, orgulho, sentimento de força". No aforismo abaixo reconhecemos que “Nós, artistas!” faz referência àqueles que negam a natureza e tratam as mulheres como posse.

\begin{abstract}
Nós, artistas! - Se amamos uma mulher, facilmente sentimos algum ódio pela natureza, ao lembrar as repugnantes funções naturais a que toda mulher está sujeita. Preferimos evitar esse pensamento; mas, se alguma vez nossa alma roça por tais coisas, ela estremece impaciente e, como disse, lança um olhar de desprezo à natureza: - sentimo-nos ofendidos, a natureza parece abusar do que nos pertence, e com as mãos mais impuras. Então fechamos os ouvidos a toda fisiologia e decretamos sigilosamente para nós mesmos: "Não quero ouvir dizer que o ser humano é outra coisa que não alma e forma!'” "O ser humano por baixo da pele" é, para todos os que amam, um horror impensável [...] (NIETZSCHE, 1882, GC, I - V, II, 59, Nós, artistas! 2012, p. 91).
\end{abstract}

Primeiramente tomemos a questão da natureza enquanto fisiologia no fragmento "se amamos uma mulher, facilmente sentimos algum ódio pela natureza, ao lembrar as repugnantes funções naturais a que toda mulher está sujeita". Entendemos por "repugnantes funções naturais" as funções fisiológicas próprias da mulher, como a menstruação e os sintomas que, muitas vezes, a acompanham; a gestação; o parto acompanhado do puerpério; a amamentação; a menopausa; nossos odores e nossas oscilações de humor em função da variação dos hormônios ao longo de um mês ${ }^{12}$, bem como em todas as etapas de nossa fisiologia feminina.

\footnotetext{
${ }^{12}$ Período correspondente a um ciclo menstrual. As alterações hormonais do ciclo menstrual podem ser quase imperceptíveis em muitas mulheres. Por outro lado, podem apresentar-se bastante exuberantes em outras mulheres, demandando tratamento medicamentoso e, por vezes, acompanhamento psíquico/psicológico.
} 
Em nossa apreciação Nietzsche critica de forma irônica a postura masculina ou dos artistas que se sentem agredidos pela natureza que insiste em lhes mostrar que as mulheres que amam, são humanas. Segue a crítica quando afirma que por isto se despreza a natureza e com ela se ofende, por abusar "daquilo que é nosso", ou seja, do corpo feminino que deve servir ao prazer do homem e cujas funções fisiológicas, repugnantes porque transformam a mulher em um humano e não mais na figura idealizada da mulher bonita, perfumada, dócil e meiga, pronta para a satisfação sexual do homem: um objeto pertencente ao homem e utilizado para seu gozo. Outras finalidades? Cuidar das suas necessidades de vida prática, ou de seus filhos, quem sabe?

Quando os homens adotam para si a noção de as mulheres são uma criação da natureza para sua satisfação sexual e para o exercício do cuidar, seja do próprio homem, de seus filhos e das suas casas, a mulher é reduzida a um objeto de posse e uso pessoal do homem, sobre qual este se sente no direito de dispor sempre que desejar. Esta relação de objetificação da mulher e de uso do seu corpo para a satisfação sexual masculina é o que abordaremos no caso de Geralda.

Ainda criança, Geralda, órfã de pai e mãe, tendo sido criada por vizinhos, foi levada, aos onze anos e analfabeta, para trabalhar na casa de uma família em cidade distante. Tratava-se de uma residência de dois andares onde no piso superior funcionava o escritório do seu patrão, um advogado. $\mathrm{Na}$ casa viviam dois meninos e outras quatro meninas com idade próxima à sua, todas filhas dos donos do imóvel. "Enquanto eles brincavam, ela era explorada no trabalho infantil. Mesmo pequena, fazia serviço de gente grande, sendo responsável pela comida, lavagem de roupas e limpeza" relata Arbex (2013, p. 143).

A dona da casa e esposa do advogado, segundo Arbex (2013), sofria constantes crises nervosas e era frequentemente internada em clínicas psiquiátricas particulares, o que fez com que Geralda, aos onze anos, se tornasse a responsável por todo o serviço da casa. Aos quatorze anos começaram os assédios do patrão e um ano depois, aos quinze anos, o estupro e a gestação. Geralda deixava agora de ser útil, não mais servia como forma de satisfação do desejo sexual: estava prenhe. Não conseguiria cuidar dos afazeres domésticos como antes e logo a gestação denunciaria que algo havia ocorrido com a menina.

Solução encontrada: Geralda foi enviada ao Hospital Colônia de Barbacena onde deu à luz um menino do qual foi separada quando este completou dois anos de idade, só voltando a reencontrálo quando adulto. Do patrão e pai da criança nunca mais teve notícias (ARBEX, 2011). A condição de Geralda é semelhante à de tantas outras mulheres que são usadas como objeto de satisfação para o prazer masculino, para quem apenas parte da fisiologia e da anatomia feminina interessa, a saber, a sexualidade e a utilidade dos corpos femininos para o alívio das tensões sexuais masculinas. Algo 
que se usa e depois pode ser descartado, não tem mais utilidade ou pode até se converter em motivo de transtorno, como seria Geralda se tivesse levado sua gestação a termo vivendo na casa do patrão.

Tomando como princípio o pensamento de Lopes (2018, p.36) ao discutir como os homens exercem seus ideais de poder a partir da existência do falo ${ }^{13}$, e como elaboram o que é feminino a partir da ausência deste, mas da presença de "um orifício para o encaixe e o prazer do falo" (p.36), entendemos que é o poder do falo que autoriza o uso dos corpos femininos como objetos para satisfação sexual, como no caso de Geralda.

Essa relação com o falo se faz presente também quando discutimos a respeito da histeria, uma patologia descrita como tipicamente feminina e relacionada à falta do falo, mais precisamente à ausência do falo para satisfazer sexualmente a mulher. Ocorre que a medida da satisfação sexual feminina, como discutido por Lopes (2008), permanece sendo elaborada e autorizada pelos homens, sendo eles quem decidem quando e em que tipo de situação há satisfação sexual feminina. E esta decisão, muitas vezes, parece ser pautada mais naquilo que pode satisfazer aos homens do que propriamente às mulheres, haja vista os casos de estupro feminino, como no caso de Geralda, onde à mulher não é facultada a escolha que poderá satisfazê-la.

Haja vista que há descritos na literatura voltada para a psiquiatria e a psicologia distúrbios relacionados aos excessos cometidos por mulheres muito ativas sexualmente, como a ninfomania ou o desejo sexual hiperativo que, de acordo com Groneman (1994) é uma condição considerada patológica que nasce da tentativa de responder a questões como "Quanto é demais? Quanto não é suficiente? Há uma quantidade saudável, normal e natural de sexo? E quem decide?”. A quem cabe decidir quando o desejo sexual feminino se torna anormal? Até hoje a questão tem sido tratada pelos homens da moral e da ciências.

Cabe acrescentar que na maioria dos estudos aqui utilizados os diagnósticos de histeria eram comuns, especialmente em se tratando de mulheres solteiras, como abordado por Engel (2004) e Wadi (2006), o que reforça a ideia de que mulheres que se satisfaziam sexualmente sem um falo eram consideradas doentes pela ciência masculina, e ainda são consideradas desviantes por grande parte da sociedade.

\footnotetext{
${ }^{13} \mathrm{O}$ poder do falo se mostra no poder de nomear, determinar, restringir, corrigir, autorizar ou proibir, sancionar a partir da sua racionalidade que, como qualquer outra, se retroalimenta. Seu raciocínio, suas necessidades, desejos, prazeres e gozos disseram primeiramente como ele se enxerga e, portanto, o que ele é: o que tem falo. A partir disso ele determinou todo o resto, inclusive o que é o feminino: o que não tem falo, mas tem um orifício para o encaixe e o prazer do falo. $\mathrm{O}$ falo se fez poder a partir daqueles que o possui e em detrimento dos corpos com ausência de falo (LOPES, 2018, p.36).
} 


\section{CONSIDERAÇÕES FINAIS}

Consideramos importante salientar que em nossa leitura sobre as mulheres nas obras de Nietzsche, encontramos uma crítica aos padrões e às normas criadas pelos homens para elaborar verdades sobre as mulheres, para nomear, classificar, autorizar comportamentos, punir as não adequações. Dentre os escritos do filósofo alemão, notabilizamos uma visão que pode ser interpretada como a de uma mulher que busca a elaboração de si como possibilidade de uma vida mais potente, como no excerto abaixo:

\footnotetext{
O que na mulher inspira respeito e com frequência temor é sua natureza, que é "mais natural" que a do homem, sua autêntica astuciosa agilidade ferina, sua garra de tigre por baixo da luva, sua inocência no egoísmo, sua ineducabilidade e selvageria interior, o caráter inapreensível, vasto, errante de seus desejos e virtudes... (NIETZSCHE, ABM, \239, p. 145).
}

Tal passagem nos remete a ideia do vir a ser, de tornar-se quem se é, proposta de Nietzsche para a possibilidade de criação de um realidade menos ressentida, para que homens e mulheres possam conhecer sua condição de animal de rebanho e elaborar outra forma de viver que seja mais potente e menos reativa (NIETZSCHE, 1882, GC, I - V. 2012). Para tanto Nietzsche propõe uma transvaloração do valores pautada na ideia do eterno de retorno do mesmo, ou seja, imaginar-se repetindo as obras da própria vida infinitas vezes. Quando este pensamento for agradável, ele simboliza uma vida saudável, sem ressentimento. Quando esta ideia se mostra perturbadora, é necessário então transvalorar os valores, ou seja, encontrar outras formas menos ressentidas de viver, como afirma o filósofo: "transvaloração de todos os valores: eis a minha fórmula para um ato de suprema autoconsciência da humanidade, que em mim se fez gênio e carne" (NIETZSCHE, EH, out-nov de 1888. Por que sou um destino, $\$ 1.2008)$.

Transvalorar valores não é tarefa fácil, requer coragem de elaboração de si e do mundo, aceitando que o mundo ordenado, linear e cronológico que a ciência nos ensina apenas existe na literatura científica. A compreensão de que o mundo é gerido pelo caos nos leva ao mais profundo entendimento de que uma vida planejada é uma ilusão e de que normas e regras, muito mais do que nos organizar, nos angustia e causam dores. Tranvalorar valores é compreender que mesmo vivendo em meio ao caos do universo é possível experimentar uma sensação de alegria, ao aceitar que a vida é potência, é devir (vira a ser) e estar aberto às possibilidades que a vida nos apresentar. A este sentimento de aceitação vida devir, da vida como possibilidade, como algo a conhecer, e 
não como algo dado, seguro e certo, e ainda assim gostar de nela estar, Nietzsche nomeou amor fati (do latim destino). Sobre o amor fati Nietzsche escreve:

\footnotetext{
Quero cada vez mais aprender a ver como belo aquilo que é necessário nas coisas. Amor-fati [amor ao destino]: seja este, doravante, o meu amor! Não quero fazer guerra ao que é feio. Não quero acusar, não quero nem mesmo acusar os acusadores. Que minha única negação seja desviar o olhar! E, tudo somado e em suma: quero ser, algum dia, apenas alguém que diz Sim! (NIETZSCHE, 1882, GC, I - V, IV, 276, Para o Ano Novo. 2012, p. 166).
}

Observamos no trecho "não quero acusar, não quero nem mesmo acusar os acusadores" a potência do amor fati, que ao contrário dos ressentidos, que se tornam os acusadores, aqueles que ditam normas e regras, aqueles capazes de transvalorar seus calores e de alcançar o amor fati não desejam nem mesmo apontar culpados. Portanto, a intenção deste escrito é a de problematizar situações sociais que nos afetam enquanto seres que compartilham juntos da vida gregária e a partir desta abordagem e de outras que a Filosofia tem colocado, pensar outras possibilidades de porvires, talvez até mais felizes e potentes do que aqueles aqui abordados.

Os fragmentos das histórias que narramos nos permite compreender como uma moral unívoca pode anular vidas, destruir singularidades, autorizar crueldades em nome de uma homogeneização, de uma igualdade que se mostra inconsistente nas resistências e insurgências registradas. A história da humanidade está repleta de exemplos de como é preciso pensar outra forma de se relacionar com a vida e com o mundo, porém elaborar essa outra forma não é tarefa simples. A filosofia de Nietzsche nos coloca a crítica a partir da qual podemos compreender como chegamos ao ponto onde estamos, e também aponta possibilidades para mudanças a serem feitas no campo individual e no campo social. Aprender o amor fati para transvalorar valores nos parece uma possibilidade e dar a conhece-la é uma importante tarefa da Filosofia.

\section{REFERÊNCIAS BIBLIOGRÁFICAS}

ARBEX, Daniela. Holocausto brasileiro. São Paulo: Geração Editorial, 2013.

DELUMEAU, Jean. História do Medo no Ocidente 1300 - 1800: uma cidade sitiada. Trad. Maria Lucia Machado e Heloísa Jahn. São Paulo: Companhia de Bolso, 2009.

ENGEL, Magali. Psiquiatria e feminilidade. IN: PRIORE, Mary Del (org). História das Mulheres no Brasil. 7. ed. São Paulo: Contexto, 2004. 
FREUD, S. Histeria (1888). In: Edição eletrônica brasileira das obras psicológicas completas de Sigmund Freud. Rio de Janeiro: Imago, V.I., s/d. Disponível em:

http://conexoesclinicas.com.br/obras-completas-de-freud/ Acesso em 26/07/2019.

GRONEMAN, Carol. Nymphomania: The Historical Construction of Female Sexuality. Journal of Women in Culture and Society. V. 19, n. 21, University of Chicago, 1994. Disponível em: https://www.jstor.org/stable/3174802? seq=1\#page scan tab contents Acesso em 26/08/2019.

LOPES, Adriana Delbó. Sobre esse gênero que não nos pertence e os poderes a nos pertencer. Kalagatos, Fortaleza, Vol.15, N.2, 2018, p. 34-55. Disponível em:

http://kalagatos.com.br/index.php/kalagatos/article/view/791/629 Acesso em 10/08/2019. Acesso em 13/07/2019.

MARESCA, S.J. A emancipação da mulher ( $\mathbb{S} 231$ - $\$ 239$, JBG/BM). Trad. Vânia Dutra de Azeredo. In: Cadernos Nietzsche, São Paulo, n.11, p 107-112, 2001. Disponível em: http://anpof.org/portal/index.php/pt-BR/ppe/user-item/15334-cadernos-nietzsche/16593-aemancipacao-da-mulher Acesso em 23/07/2019.

MIRANDA, Carlos Alberto C. "Delírios femininos": vivências de mulheres internadas no Hospital de Alienados (Recife/PE, 1927-1936). Mneme Revista de Humanidades da Universidade Federal do Rio Grande do Norte, v. 17 n. 38 - Caicó: Dossiê História e Tecnologias da Saúde, 2016 (56-82). Disponível em: https://periodicos.ufrn.br/mneme/issue/view/562. Acesso em 05/06/2019.

MOURA, Bruno H. e POPPERL, Mariana S. Belas, recatadas e loucas: mulheres no Manicômio Judiciário de São Paulo. Revista Humanidades em Diálogo/ Dossiê: Gênero presença e representações/ v.9, 2019. Disponível em: http://www.revistas.usp.br/humanidades/article/view/154263 Acesso em 05/06/2019.

MUÑOZ, Pedro Felipe Neves de. Degeneração atípica: uma incursão ao arquivo de Elza [pdf]. Dissertação de Mestrado do Programa de Pós Graduação em História das Ciências e da Saúde da Fundação Oswaldo Cruz/Casa de Oswaldo Cruz. Rio de Janeiro, 2010. Repositório Institucional da Fiocruz. Disponível em: https://www.arca.fiocruz.br/handle/icict/6099 Acesso em 14/08/2019.

NIETZSCHE, Friedrich Wilhelm. A gaia Ciência (GC, I - V - 1882). Trad. Paulo César de Souza. Col. Obras de Nietzsche. São Paulo: Companhia das Letras, 2012.

Assim falou Zaratustra: um livro para todos e para ninguém (ZA I IV - 1883). Trad. Mário da Silva. 13a ed. Rio de Janeiro: Civilização Brasileira, 2005.

Genealogia da Moral: uma polêmica (GM - 1887). Trad. Paulo César de Souza. Col. Obras de Nietzsche, $2^{a}$ ed. São Paulo: Companhia das Letras, 1998.

Além do bem e do mal: Prelúdio a uma Filosofia do Futuro (ABM1886). Trad. Paulo César de Souza. Col. Obras de Nietzsche, $2^{a}$ ed. São Paulo: Companhia das Letras, 1992.

Ecce Homo (EH, out-nov de 1888). Trad. Paulo César de Souza. São

Paulo: Companhia das Letras, 2008. 
OLIVEIRA, Pedro Henrique F. D. A patologização do feminino: gênero, crime e loucura estudos de caso de mulheres internadas no Manicômio Judiciário de Barbacena. Revista de História Unisinos, v. 23, n. 2. Fundação Oswaldo Cruz/Casa de Oswaldo Cruz. Programa de Pós-Graduação em História das Ciências e da Saúde. Rio de Janeiro:RJ, 2019. Disponível em: http://revistas.unisinos.br/index.php/historia/article/view/hist.2019.232.14/60747033 Acesso em $14 / 08 / 2019$.

PASCHOAL, Antonio E. As formas do ressentimento na filosofia de Nietzsche. Revista de Filosofia Philósophos, v. 13, n.1. Goiânia, Go: 2008 (p.11-33). Disponível em: http://anpof.org/portal/index.php/pt-BR/ppe/user-item/15193-philosophos/16121-as-formas-doressentimento-na-filosofia-de-nietzsche Acesso em 04/07/2019.

VILLARI, Rafael, A. É possível uma história da histeria? Revista de Ciências Humanas, Florianópolis: EDUFSC, n.29, p.131-145, abr. de 2001. Disponível em:

https://periodicos.ufsc.br/index.php/revistacfh/article/view/24038/21490 Acesso em 25/06/2019.

VOCARO, Juliana Suckow. A Construção do Moderno e da Loucura: Mulheres no Sanatório Pinel de Pirituba (1929 - 1944) [PDF]. Dissertação de Mestrado do Programa de Pós Graduação em História Social da Universidade de São Paulo. São Paulo, 2011. Disponível em: http://www.teses.usp.br/teses/disponiveis/8/8138/tde-31102011-103753/pt-br.php Acesso em 14/08/2019.

WADI, Yonissa M. Experiências de vida, experiências de loucura: algumas histórias sobre mulheres internas no Hospício São Pedro (Porto Alegre, RS, 1884-1923). Revista de História Unisinos, v. 10 n. 1 - janeiro/abril de 2006 (65-79). Disponível em: http://revistas.unisinos.br/index.php/historia/article/view/6171 Acesso em 14/06/2019. 